\title{
Alfa-sinukleina biomarkatzaile gisa Parkinson gaixotasunaren diagnostikoan
}

\section{(Alpha-synuclein as a diagnostic biomarker in Parkinson disease)}

\author{
Ane Murueta-Goyena ${ }^{1,2}$, Maider Zubelz $u^{3}$, Teresa Morera-Herreras ${ }^{* 1,3}$ \\ ${ }^{1}$ Gaixotasunen Neurodegeneratiboen taldea, \\ Biocruces Bizkaia Osasun Ikerketa Institutoa, Barakaldo, Bizkaia \\ 2 Prebentzio Medikuntza eta Osasun Publikoa Saila, \\ Euskal Herriko Unibertsitatea (UPV/EHU), Leioa, Bizkaia \\ ${ }^{3}$ Farmakologia Saila. Medikuntza eta Erizaintza Fakultatea \\ Euskal Herriko Unibertsitatea (UPV/EHU), Leioa, Bizkaia
}

\begin{abstract}
LABURPENA: Parkinson gaixotasuna ohiko gaixotasun neurodegeneratiboa da, patologikoki Lewy gorputzen presentziagatik eta neurona dopaminergikoen galera progresiboagatik bereizten dena. Gaur egun, Parkinson gaixotasunaren diagnostikoa irizpide klinikoetan oinarrituta dago; hau da, gorputz -adarren dardara, mugimenduen moteltasuna edo muskuluen gogortasuna bezalako sintoma motorrak agertzen direnean diagnostikatzen da. Hala ere, sintoma motorrak azaleratzen direnerako, mesentzefaloko neurona dopaminergikoen erdia baino gehiago galdu direla uste da. Gainera, Parkinsonaren diagnostiko klinikoa erronka bat denez, ohikoak dira diagnostiko okerrak. Horrek argi uzten du gaixotasunaren berariazko diagnostikorako biomarkatzaileak behar direla, batez ere fase goiztiarretan. Lewyren gorputzak aberatsak dira alfa-sinukleina ( $\alpha$-sinukleina) proteinatan, eta hauek funtsezko eginkizuna dute Parkinson gaixotasunaren patogenesian. Hori dela eta, $\alpha$-sinukleina baliagarria izan daiteke Parkinsonaren biomarkatzaile gisa. Berrikuspen honen helburua, beraz, gorputzeko fluido desberdinetan $\alpha$-sinukleinaren eta haren proteoformen neurketaren erabilgarritasun-diagnostikoari buruzko ebidentzia laburbiltzea da. Izan ere, espezifikoak, sentikorrak eta eskuragarriak diren biomarkatzaileak identifikatzea ezinbestekoa da Parkinson gaixotasuna aldatzeko dauden eta etorkizunean izango diren tratamenduei dagokienez. Nahiz eta hautagai nagusia $\alpha$-sinukleina likido zefalorrakideoan (LZR) neurtzea izan den, LZR biltzeko prozedura nahiko inbaditzailea da, eta ez da egokia ingurune kliniko gehienetan. Ondorioz, odol-plasma, listua eta malkoa bezalako biofluidoetan ikertu da proteina honen eta haren proteoformen presentzia. Ikerketa hauen emaitzen arabera, $\alpha$-sinukleina fosforilatua eta oligomerikoa izan daitezke hautagai egokienak Parkinson gaixotasunaren diagnostikorako. Orain arte $\alpha$-sinukleinaren neurketak muga tekniko anitz izan dituen arren, azken urteetan sortutako tekniken bitartez entseguen errepikakortasuna eta fidagarritasuna nabarmen areagotu da. Beraz, hautagai nagusiek Parkinsonaren diagnostikorako biomarkatzailegisa izan dezaketen potentziala hurrengo urteetan egiaztatzea espero da.

HITZ GAKOAK: Parkinson gaixotasuna, alfa-sinukleina, biomarkatzailea, likido zefalorrakideoa, odol-plasma, listua, malkoa, biofluidoa.
\end{abstract}

\begin{abstract}
Parkinson disease (PD) is a common neurodegenerative disease, characterized pathologically by the presence of Lewy bodies and the progressive loss of dopaminergic neurons. Currently, the diagnosis of PD is based on clinical criteria; that is, it is diagnosed when motor symptoms appear such as limb tremor, slowness of movement or muscle stiffness. However, by the time motor symptoms appear, more than half of the dopaminergic neurons in the midbrain have been lost. Furthermore, as clinical diagnosis of PD is challenging, misdiagnosis is common. This highlights the need for disease-specific and early-stage biomarkers. Lewy bodies are rich in $\alpha$-synuclein protein, who plays a fundamental role in the pathogenesis of PD. Therefore, $\alpha$-synuclein may be useful as a PD biomarker. Therefore, the objective of this review is to summarize the efficacy of body fluid $\alpha$-synuclein and its proteoforms measurements in the detection of PD. In fact, the identification of specific, sensitive, and non-invasive biomarkers is essential especially in regard to existing and future disease modifying treatments. Although the main candidate has been the measurement of $\alpha-$-synuclein in cerebrospinal fluid (CSF), CSF collection procedure is quite invasive and unsuitable in most clinical settings. Consequently, the presence of this protein and its proteoforms in biofluids such as blood plasma, saliva and tears has been investigated. Based on the results of these studies, phosphorylated and oligomeric $\alpha$-synuclein are the best candidates for PD diagnosis. Until now, the measurement of $\alpha$-synuclein has had multiple technical limitations, but the repeatability and reliability of immunoassays created in the last years has increased considerably. Therefore, it is expected that the potential of the main candidate biomarkers for PD diagnosis will be verified in the upcoming years.
\end{abstract}

KEYWORDS: Parkinson disease, alpha-synuclein, biomarker, cerebrospinal fluid, plasma, saliva, tear, biofluid.

\footnotetext{
* Harremanetan jartzeko / Corresponding author: Teresa Morera-Herreras. Farmakologia Saila. Medikuntza eta Erizaintza Fakultatea (UPV/EHU), Leioa, Bizkaia. - teresa.morera@ehu.eus - https://orcid.org/0000-0002-7601-4914
}

Nola aipatu / How to cite: Martínez-Murueta-Goyena, Ane; Zubelzu, Maider; Morera-Herreras, Teresa (2021). "Alfa-sinukleina biomarkatzaile gisa Parkinson gaixotasunaren diagnostikoan». Ekaia, 41, 2021, 11-29. (https://doi.org/10.1387/ekaia.22751).

Jasotze-data: 2021, apirilak 23; Onartze-data: 2021, uztailak 8.

ISSN 0214-9753 - eISSN 2444-3581 / (c) 2021 UPV/EHU

(i)() $\odot$ Lan hau Creative Commons Aitortu-EzKomertziala-LanEratorririkGabe 4.0 Nazioartekoa

lizentzia baten mende dago 


\section{SARRERA}

Parkinson gaixotasuna nahasmendu neurodegeneratibo ohikoena da, Alzheimer gaixotasunaren atzetik. Gaur egun, 60 urtetik gorako biztanleriaren \% 1-2ri eragiten dio mundu-mailan, eta 80 urtetik gorako biztanleen $\%$ 4ri [1]. Europan eta Espainian antzekoak dira gaixotasunaren prebalentzia- eta intzidentzia-datuak. Hain zuzen ere, Estatu Espainiarrean gutxienez 300.000 gaixo daude, eta urtero 10.000 biztanleko kasu berri bat diagnostikatzen da [2]. Euskadin 8.000 pertsonak baino gehiagok pairatzen dute gaitz hau, eta Bizkaian soilik 4.400 kasu inguru daude diagnostikatuta. Parkinson gaixotasunaren prebalentziak gora egiten du adinarekin, eta munduko biztanleriaren zahartzearen ondorioz, datozen hamarkadetan nabarmen gorago egingo duela aurreikusten da [3]. 2016. urtean egindako «Global Burden of Disease» ikerketaren arabera, gaixotasun neurologikoen artean, Parkinsona da hazkunde azkarrenetarikoa izaten ari dena, adinaren araberako prebalentzia-datuei dagokienez. 1990etik 2016ra, Parkinson gaixotasuna zuten pertsonen kopurua bikoitza baino gehiago hazi zen munduan, eta 6,1 milioi pertsonara iritsi zen [4]. Aurreikusten da 2040. urterako kopuru hau 12 milioi pertsona baino gehiagora iritsiko dela [3]. Hori dela eta, karga sozial eta ekonomikoa areagotu egingo dira, gaur egun eskuragarri dauden tratamenduak baino tresna terapeutiko eraginkorragoak identifikatzea lortzen ez bada.

\section{PARKINSON GAIXOTASUNA: EZAUGARRI KLINIKOAK}

\subsection{Sintomatologia klinikoa}

Parkinson gaixotasunaren sintomatologiari dagokionez, sintoma motorrak dira ezagunenak; hala nola, atsedenaldiko dardara, muskuluen zurruntasuna, gorputz-jarreraren ezegonkortasuna eta bradikinesia edo mugimenduen moteltasuna [5, 6]. Gaixotasuna sintomatologia-motor bereizgarri hori agertzen denean diagnostikatzen da. Aipatutako sintoma motor horiek neurona dopaminergikoen endekapenarekin lotuta daude [5,6]; izan ere, substantia nigra pars compacta-ko (SNc) neurona dopaminergikoen $\% 60$ inguru galdu denean eta bide nigroestriataleko dopamina-edukia \% 60-90 murriztu denean agertzen dira [7].

Sintoma ez-motorrak ere agertzen dira: disfuntzio autonomoa (hipotentsio ortostatikoa eta esfinterren disfuntzioa), usaimen-urritasuna, aldartearen asaldurak (depresioa eta antsietatea, adibidez), defizit kognitiboak edota loaren nahasmenduak. Sintoma ez-motor horietako gehienak sintoma motorrak baino lehen (gaixotasuna diagnostikatu aurretik) agertzen dira, eragin zuzena dute gaixoen bizi-kalitatean eta ez dute lotura zuzenik sistema dopaminergikoaren endekapenarekin $[1,6]$. 


\subsection{Tratamendua}

Gaur egun, Parkinson gaixotasunak sendaezina izaten jarraitzen du, eta eskura dauden tratamenduak sintoma motorrak arintzera bideratuta daude; hau da, tratamendu sintomatikoak baino ez dira. Oraindik ez dago terapiarik neuronen heriotzaren progresioa moteltzeko edo geldiarazteko, eta are gutxiago sintomak agertzen direnerako sortutako kaltea lehengoratzeko. Gaixotasunaren aldi goiztiarra tratatzeko, tratamendu farmakologikoa da lehen aukera, eta tratamendu kirurgikoa, aldiz, medikamentuak onartzen ez dituzten pazienteekin erabiltzen da.

Tratamendu farmakologikoek dopamina endogenoaren gabezia zuzentzea izan ohi dute helburutzat [8]. Dopaminaren aitzindari metabolikoa den levodopa (L-DOPA) da eskuragarri dagoen farmako eraginkorrena. L-DOPA hesi hematoentzefalikoa zeharkatzeko gai da, eta striatum-era heltzen denean, bertan biziraun duten terminal nigroestriataletan L-DOPA dopaminara eraldatzen da [9]. Horrela, striatum-eko transmisio dopaminergikoa hobetu eta sintoma motorrak arintzen ditu; batez ere, mugimenduen geldotasuna eta zurruntasuna. Hala ere, L-DOPAk ez du prozesu neurodegeneratiboa geldiarazten, eta eraginkortasuna murriztu egiten da denborarekin. Horrek mugikortasun- eta diskinesia-arazoak sortzen ditu [6]. Diskinesiak dosiaren eta tratamenduaren iraupenaren araberakoak diren ezohiko eta nahigabeko mugimendu hiperzinetikoak dira, eta L-DOPA eman zaien pazienteen \% 30ek jasan ditzake. L-DOPAren eraginez, transmisio dopaminergikoan eraldaketa bat gerta daitekeela proposatu da, eredu tonikotik eredu fasikora; eta, hortaz, dopamina sinaptikoaren maila handitu egin daiteke nukleo kaudatu eta putamen-ean. Transmisio dopaminergikoaren aldaketa horrek striatum-eko neurona espezifiko batzuetan dauden glutamato hartzaileen hiperfosforilazioa eragin dezake. Ondorioz, neurona horiek sentikorrago bihur daitezke proiekzio glutamatergikoen aurrean. Horrek diskinesiak agertzea eragin dezake [10]. Beraz, gaur egun, eragin anti-glutamatergikoak dituen amantadina izeneko farmakoa da L-DOPAk eragindako diskinesiei aurre egiteko farmakorik eraginkorrena [11,12].

Agonista dopaminergikoak ere erabil daitezke Parkinson gaixotasuna tratatzeko. Hartzaile dopaminergikoetara lotuz, konposatu horiek nolabait dopamina ordezkatzen dute [8]. Hasierako monoterapia gisa edo L-DOPArekin konbinatuta erabil daitezke. Halaber, ez dira L-DOPA bezain eraginkorrak (apomorfina izan ezik), baina farmako horien erabilerak L-DOPAren tratamendua eta horren ondorioz agertzen diren diskinesiak atzeratzea ahalbidetu dezake [12].

Hurbilketa kirurgiko gisa, garunaren estimulazio sakona deritzon teknika erabiltzen da sintomak oso larriak direnean edo tratamendu farmakologikoak eraginik izan ez duenean. 


\subsection{Diagnostiko goiztiarraren beharra}

Arestian aipatu bezala, neurona dopaminergikoen endekapena nabarmena da diagnostikora iristen den unean eta horrek tratamenduen eraginkortasuna mugatzen du. Hori dela eta, agerian geratzen da tratamenduak arrakasta izateko ahalik eta lasterren ezarri behar dela. Parkinsonaren aurkako terapian, diagnostiko goiztiarra ahalbidetuko luketen biomarkatzaile molekular fidagarriak aurkitzea benetako erronka eta lehentasuna da. Biomarkatzaile horiek ahalbidetuko lukete Parkinson gaixotasuna antzeko sintomak partekatzen dituzten beste gaixotasun batzuetatik bereiztea eta, era berean, prozesu diagnostikoa hobetzea, pronostiko zehatzagoa egitea, eta gaixotasunaren progresioaren zein terapiaren eraginkortasunaren jarraipena egitea $[8,13]$.

Biomarkatzaileak gaixotasunaren egoera, haren progresioa edo terapiaren eragina era objektiboan neurtzen laguntzen duten seinale edo adierazle biologikoak dira. Parkinsonaren diagnostiko klinikoa neurona kopuru handia endekatu denean gertatzen denez, hurrengo biomarkatzaile motak detektatzeko beharra dago: (1) sintoma motorrak agertu aurretik edo etapa preklinikoan agertzen diren biomarkatzaileak; (2) gaixotasuna pairatzeko arriskua dagoela adierazten duten biomarkatzaileak; eta (3) Parkinsonaren diagnostikoa egin ondoren, gaixotasunaren etorkizuna aurreikusten lagundu dezaketen biomarkatzaileak [14].

Gaur egun, ikertzen ari diren Parkinson gaixotasunaren biomarkatzaileak lau talde nagusitan bereiz daitezke: klinikoak, irudi bidezkoak, biokimikoak eta genetikoak. Ikertu diren biomarkatzaile hautagai guztien artean, alfa-sinukleina proteinaren ( $\alpha$-sinukleina) forma desberdinak kontsideratzen dira baliagarrienak; hala nola, forma disolbagarria, agregatua edo itzulpenaren ostean eraldatutakoa [8].

\section{PARKINSON GAIXOTASUNAREN NEUROPATOLOGIA}

Egun, Parkinsonaren diagnostikoa espezifikotasun handiarekin egin daiteke, irizpide klinikoak erabiliz [15]. Hala ere, diagnostikoa berresteko, ezinbestekoa da azterketa neuropatologikoa egitea. Azterketa horri esker, gaixotasun neurodegeneratiboak ez izan arren Parkinson gaixotasunaren antzeko sintomak erakusten dituzten beste patologia batzuk identifika daitezke; adibidez, Parkinsonismo farmakologikoa, Parkinsonismo baskularra edo paralisi supranuklear progresiboa, besteak beste [16].

Parkinsona gaixotasun neurodegeneratiboa da, eta, beraz, neuronen narriadura eta heriotza da gaixotasunaren ezaugarri nagusia [17]. Neurodegenerazioa eragiten duten mekanismo zehatzak ezagutzen ez diren arren, gaixotasun neurodegeneratiboetan gaizki tolestutako proteinak garuneko 
zeluletan metatzen direla behatu da. Hain zuzen ere, gaixotasun neurodegeneratibo mota nagusietan proteinen agregatuak aurkitzen dira azterketa neuropatologikoan. Uste da ohiz kanpoko metaketa horrek estres oxidatiboa eta inflamazioa areagotzen dituela eta, ondorioz, zelulen biziraupenean eragin kaltegarria duela. Agregatu horien konposizioa eta kokapena desberdina da diagnostiko klinikoaren arabera [18]. Azken urteetan, proposatu da agregatu proteiniko jakin batek gaixotasun neurodegeneratibo konkretu bat sor dezakeela. Hala ere, ikuspegi horrek sinplistegia dirudi. Izan ere, proteina berberaren metaketa duten gaixoek diagnostiko kliniko desberdina izan dezakete, hainbat faktoreren arabera; hala nola, proteinaren kokapena zelula-mailan eta, garuneko eskualdearen arabera, neurodegenerazio-maila, sintoma klinikoak, aurrekari genetikoak, eta abar. Era berean, diagnostiko kliniko jakin bat duten gaixoetan ohikoa da hainbat proteinaren metaketa gertatzea [19].

Neurodegenerazioa eragin dezakeen lehen kausa estres oxidatzailea izan daitekeela iradoki da [20]. Ugaztunek neuronen kontsumo energetiko altua dute, eta mitokondrietan, zelula energiaz hornitzen duen organuluan, kalteren bat gertatuz gero, erradikal askeak areagotu daitezke, eta horiek izango dira min oxidatzailearen eragile. Bestalde, neurona guztiak ez dira berdinak, eta ager daitezkeen oinazeen aurrean ez dute berdin erantzuten. Adibidez, Parkinson gaixotasunean neurodegenerazioarekiko bereziki sentikorrak dira garuneko substantia nigra edo striatum eskualdeak, adibidez [21].

Gainera, jakina da neuronen morfologia eta jarduera sinaptikoa eta, ondorioz, neuronen biziraupena proteinen itzulpen-jardueraren mende daudela. Horregatik, hainbat faktore patogenikoren eraginez proteinen sintesia murrizten bada, mekanismo neurodegeneratiboak martxan jarriko liratekeela uste da [22]. Izan ere, duela ia 50 urte proposatu zuten Johnson eta Strehlerrek erribosomen biogenesian akats batek prozesu neurodegeneratiboak eragiten dituela [23]. Berrikiago, hainbat koadro neurodegeneratibotan nukleoloaren eta proteinen sintesi-makineriaren disfuntzioan jarduten duten mekanismo zelular eta molekular batzuk deszifratu dira; batez ere Alzheimerren gaixotasunean, Parkinson gaixotasunean, alboko esklerosi amiotrofikoan eta bizkarrezur-muineko atrofia muskularrean [24]. Azkenik, ondorio orokor gisa, gaixotasun neurodegeneratiboek alterazio larriak eragiten dituzte proteinen biogenesiaren eta degradazioaren zikloan eta haien kalitate-kontrolean. Asaldura horiek estres zelularra eragiten dute, batez ere nukleoloan eta erretikulu endoplasmatikoan, eta, ondorioz, gaizki tolestutako proteinen erantzuna aktibatzen da (UPR, «Unfolded protein response») [25]. Hori dela eta, proteinek ezohiko konformazioak hartzen dituzte, eta ondorioz, agregatu anormalak eta zuntzak sortzen dituzte. Beraz, gaixotasun neurodegeneratibo nagusien funtsezko ezaugarriak hauek dira: proteinen metaketa zelulen barnean edo kanpoaldean, eta espezie oli- 
gomerikoen ekoizpena eta metaketa. Anti-ubikitina immunohistokimiaren bidez modu ez-espezifikoan detekta daitezke proteinen inklusio horiek, bai zelula barnekoak, bai zelulaz kanpokoak [26]. Gaur egun, gaixotasun bakoitzean dauden proteinak era zehatzagoan identifika daitezke.

\subsection{Asaldura makroskopikoak}

Azterketa neuropatologikoan, lehenik eta behin, asaldura makroskopikorik badagoen aztertzen da [27]. Ebaluazio horretan garunaren kanpoaldeko ezaugarriak aztertzen dira, eta, han, garuneko zirkunboluzioen azalera eta haien arteko tartea ebaluatu behar dira, balizko atrofia kortikalaren zantzuak adieraz baititzakete. Gainera, meningeen opakutasuna, zerebeloaren kanpo-morfologia eta enbor entzefalikoaren ezaugarriak aztertzen dira. Zehazki, Parkinson gaixotasunean, garuneko gainazalak ez du alterazio nabarmenik erakusten, edota oso atrofia arina erakusten du [27]. Behin kanpoaldeko azterketa amaituta, entzefaloaren eta enbor entzefalikoaren ebaketa koronalak egiten dira. Lortutako laginetan SNc-ren eta locus coeruleus-aren despigmentazio-maila erregistratzen da, bi horien despigmentazioa Parkinson gaixotasunaren funtsezko ezaugarria baita. Aldiz, nukleo kaudatu, putamen eta globus pallidus-ek ez dute aldaketa makroskopikorik erakusten, oro har [27].

\subsection{Asaldura mikroskopikoak}

Parkinsonaren diagnostiko neuropatologikoa egiteko orduan, funtsezko aurkikuntza histologiko batzuk daude; hala nola, neuronen galera nabarmena substantia nigra-n eta Lewyren gorputzak edo neuritak aurkitzea [28] (1. irudia).

Lewyren gorputzak neuronen zitoplasman kokatutako egiturak dira. Oro har, egitura zirkularra dute, eta erdigune hialinoa halo periferiko batez dago inguratuta. Lewyren neuritak prozesu neuronaletan kokatzen dira. Lewyren gorputzak eta neuritak mesentzefaloko gune pigmentatuetan aurkitu daitezke, eta kaltetutako eremu horietan, galtze neuronala eta, Lewyren gorputzarekin batera, gliosia eta makrofagoen presentzia ere nabarmentzen dira [29]. Maila ultraestrukturalean, Lewyren gorputzak material granular trinkoz, antolamendu erradiala duten gorputz hariztiez eta 10-15 nm inguru neurtzen duten besikula-egiturez osatuta daude. Lewyren gorputzen eta neuriten osagai nagusia a-sinukleina proteina da [30]. Proteina hau era fisiologikoan agertzen da garun osasuntsuan, eta neuronen arteko komunikazioa ahalbidetzen du. Parkinson gaixotasunean a-sinukleina era patologikoan metatzen da neuronetan, eta horrek beste hainbat proteinaren metaketa eragiten du; hala nola sistema autofagikoan, egiturako elementuekin eta seinaleen fosforilazio eta transdukzioarekin lotutako proteinen metaketan. 


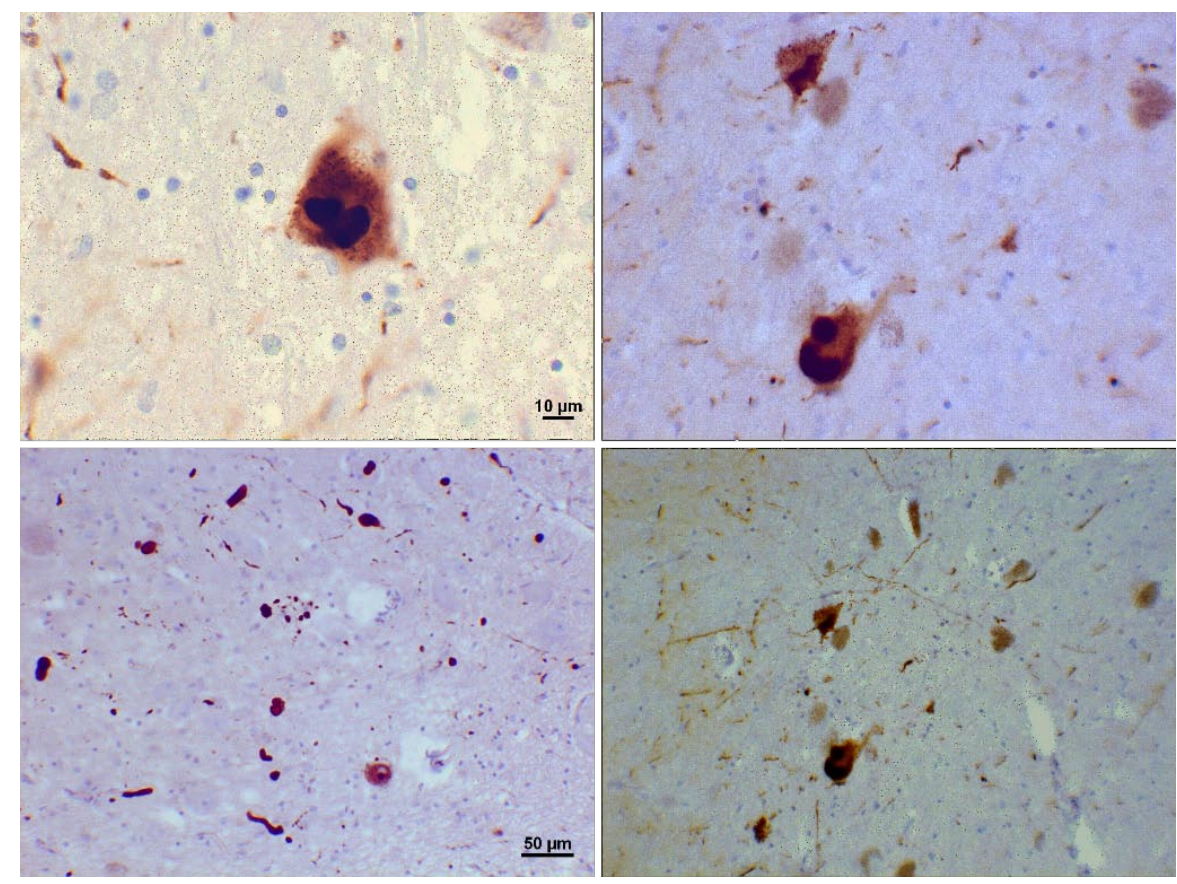

1. irudia. Parkinson gaixotasuna duen paziente baten substantia nigra-ko mikroargazkiak. Irudi hauek Lewyren gorputzak eta Lewyren neuritak erakusten dituzte handipen desberdinetan. Goiko panelean, alfa-sinukleinaren inklusio intraneuronalak erakusten dira, Lewyren gorputzak osatzen (60x handipena). Beheko panelean, Lewyren neuritak, hainbat tamainatako Lewyren gorputz biribilduak eta hari formako Lewy gorputzak erakusten dira (20x handipena). Suraj Rajan-en argazkia. Artxibo honek Creative Commons Attribution-ShareAlike 3.0 Unported lizentzia du.

\subsection{Braakek deskribatutako fase klinikoak}

Braaken sailkapena Parkinsonaren estadio desberdinak sailkatzeko erabiltzen den eskala da [31]. Sei estadio sekuentzial eta gehigarri desberdintzen dira, eta fase kliniko desberdinekin korrelazioa dute (1. taula). Braaken sailkapena aurkikuntza neuropatologikoetan oinarritzen da, eta Lewyren gorputz eta neuritetako a-sinukleinaren kokapenaren arabera egiten da. Parkinson gaixotasunaren aurkikuntza patologikoek norabide kaudorostralari jarraitzen diote. Hasiera batean, Lewyren gorputzak enbor entzefalikoko egituretan aurkitzen dira, gero mesentzefaloko egituretan, ondoren aurreko garuneko egitura ez-kortikaletan (amigdala, nukleo hipotalamikoak, eta abar) eta azkenik garun-kortexera hedatzen dira. Lewyren gorputzak erraboil-mailan daudenean, sintoma ez-motorrak agertzen dira; 
hala nola, esna-aldi eta loaldi zikloak eraldatzen dira eta loaren REM faseko asaldurak agertzen dira. Fase hori aurre-sintomatikoa dela esan ohi da, diagnostikorako behar diren sintoma motorrak oraindik ez direlako agertu [32]. Enbor entzefalikoko egiturak kaltetzen direnean, sintoma motorrak agertzen dira, eta egitura linbikoak eta kortexa narriatzen direnean, berriz, dementzia-sintomak nabarmentzen dira.

1. taula. Parkinson gaixotasunaren estadio desberdinak Braaken sailkapenaren arabera.

\begin{tabular}{c|llc}
\hline Estadioa & \multicolumn{1}{|c}{ Kaltetutako egiturak } & \multicolumn{1}{c}{ Sintomak } & \multicolumn{1}{c}{ Fasea } \\
\hline I & Usaimen erraboila & Usain-galera & Aurre-sintomatikoa \\
\hline II & $\begin{array}{l}\text { Locus coeruleus } \\
\text { Rafe nukleoa, nukleo pendunkulo- } \\
\text { pontinoa }\end{array}$ & $\begin{array}{l}\text { Lo zikloen } \\
\text { asaldura }\end{array}$ & Aurre-sintomatikoa \\
\hline III eta IV & Sistema dopaminergikoa & $\begin{array}{l}\text { Sintoma motore } \\
\text { klasikoak }\end{array}$ & Sintomatikoa \\
\hline V eta VI & Sistema linbikoa eta neokortexa & $\begin{array}{l}\text { Sintoma kognitibo } \\
\text { eta psikiatrikoak }\end{array}$ & Sintomatikoa \\
\hline
\end{tabular}

\section{ALFA-SINUKLEINA}

$\alpha$-sinukleina 140 aminoazidoz osatutako eta 3 domeinuetan banatutako proteina da: amino-muturra, karboxilo-muturra eta mutur horien arteko osagai ez-amiloidea. Halaber, $\alpha$ - eta $\beta$-helize egiturak har ditzakeen proteina da. Lehen egituraren eraketan amino-muturrak hartzen du parte, eta bigarren egituraren osaketan, aldiz, osagai ez-amiloideak [33, 34].

Parkinson gaixotasunaren ezaugarri klinikoak azaldu direnean aipatu den bezala, ikertzen ari diren Parkinsonaren biomarkatzaileen artean, $\alpha$-sinukleina proteinaren forma desberdinen determinazioa izan daiteke diagnostikorako erabilgarriena.

$\alpha$-sinukleina fisiologikoa proteina disolbagarria da. Zitosolean dagoenean forma monomerikoa izaten du, eta mintzeko lipidoetara lotuta dagoenean, berriz, forma oligomerikoa hartzen du eta tetrameroak osatzen ditu. Tetramero horiek helikoidalki tolesten dira, eta $\alpha$-helize egitura hartzen dute [35]. Baldintza patologikoetan, $\alpha$-sinukleinaren tolestura desegokiaren ondorioz, domeinu ez-amiloideak $\beta$-helize egitura hartzen du, eta proteinaren egitura sekundario horrek hedatzeko eta zuntz erako agregatuak osatzeko joera handia du [36]. Tolestura desegokia hainbat faktorek bultza dezakete; hala nola, mutazio genetikoek eta proteinaren itzulpenaren ondorengo aldaketek (fosforilazioak, adibidez) [37]. 
$\alpha$-sinukleinaren adierazpena altua da garunean, eta nerbio-bukaera presinaptikoetan kokatzen da gehienbat [38]. Hala ere, $\alpha$-sinukleinaren hainbat proteoforma (fosforilatua edo oligomerikoa, adibidez) gorputzeko fluido desberdinetan ere aurkitu daiteke; esate baterako, likido zefalorrakideoan (LZR), plasman, malkoetan edota listuan [34] (2. irudia).

\subsection{Alfa-sinukleinaren mailak likido zefalorrakideoan}

LZR biofluidoa nerbio-sistema zentraletik hurbil dagoenez, prozesu patologiko aktiboen markatzaile diagnostikoen iturri ezin hobea izan daiteke. $\alpha$-sinukleina LZRan neurtu da hainbat immunosaiakuntza-teknikaren bidez: ELISA (Enzyme-Linked ImmunoSorbent Assay), immunoelektrokimiolumineszentzia edo xMAP® teknologia, besteak beste. Ikerketa horien emaitza gehienek erakusten dute LZRan $\alpha$-sinukleinaren maila totala Parkinsona duten pazienteen artean txikiagoa dela, pertsona osasuntsuekin eta beste kontrol neurologiko batzuekin alderatuta [39-42]. Hala ere, LZRan $\alpha$-sinukleina totalaren balioak asko aldatzen dira azterlanen artean. Aldakortasun hori pazienteen heterogeneotasun klinikoaren (adina, gaixotasunaren iraupena edo larritasuna, medikazioa, eta abarren) ondorio izan daiteke [43]. Laginen odol-kutsadura eta analisi-teknikek eman ditzaketen emaitza desberdinak ere aldakortasun-iturri garrantzitsuak izan daitezke. Bestetik, datuek erakusten dute LZRko $\alpha$-sinukleina totalaren neurketa ez dela diagnostikorako tresna fidagarria. Izan ere, beste gaixotasun batzuetan ere LZRko $\alpha$-sinukleina-mailak murriztu egiten direla ikusi da; esaterako, atrofia multisistemikoan, Lewyren gorputzen dementzian edo sinukleopatiarik gabeko gaixotasun neurodegeneratiboetan [44, 45].

Emaitza horiek ikusita, ikuspegi patologikotik espezifikoagoak diren bestelako $\alpha$-sinukleina espezieak aztertu dira; fosforilatua eta oligomerikoa, hain zuzen ere. $\alpha$-sinukleina fosforilatuak Lewyren gorputzetan aurkitzen den $\alpha$-sinukleina guztiaren \% 90 osatzen du; hau da, Lewyren gorputzen osagai nagusia da [37]. Ikerketa gutxi batzuen arabera, $\alpha$-sinukleina fosforilatuaren maila altuagoa da Parkinson gaixotasuna duten pazienteetan kontrol osasuntsuetan baino. Gainera, $\alpha$-sinukleina fosforilatua/totala ratioa Parkinson pazienteetan handiagoa da, baina gainjartze handia hauteman da gaixo- eta kontrol-taldeen artean [46]. Hala ere, $\alpha$-sinukleina espezie horri buruz egindako ikerketak ez dira nahikoak, eta ikerketa horietako askotan ezin izan dute proteina honen maila modu fidagarrian neurtu, $\alpha$-sinukleina fosforilatua oso kontzentrazio baxuetan aurkitzen delako LZRan [37].

Bestalde, ikerketek $\alpha$-sinukleina oligomerikoak Parkinson gaixotasunaren fisiopatologian funtsezko eginkizuna izan dezakeela adierazten dute. Izan ere, lehenik, $\alpha$-sinukleinako oligomeroak sortzen dira, eta ondoren, Lewyren gorputzetako amiloide helduetan metatzen dira. Gainera, ikerlanek modu sendoan erakusten dute Parkinsona duten pazienteek $\alpha$-si- 
nukleina oligomerikoaren kontzentrazio handiagoak dituztela kontrolekin alderatuta [46-51]. Hala eta guztiz ere, ez dago daturik Parkinson gaixotasuna beste gaixotasun batzuetatik bereizteko $\alpha$-sinukleina espezie horrek izan dezakeen garrantziari buruz.

\subsection{Alfa-sinukleinaren mailak odol-plasman}

$\alpha$-sinukleina odolean ere neur daiteke [52], baina laginak globulu gorriekin kutsatzen badira edo prestatzen diren bitartean hemolisia sortzen bada, plasman neurtutako $\alpha$-sinukleinaren balioak asko alda daitezke [53]. Horregatik, globulu gorriz kutsatutako odol-plasmaren laginetan, $\alpha$-sinukleina mailak nabarmen gainestimatuta daude. Egindako ikerlanetan lortutako emaitzen arteko desberdintasunak azaldu ditzake horrek. Parkinsona duten pazienteetan $\alpha$-sinukleina totala plasman neurtzean eta kontrolekin alderatzean egoera desberdinak deskribatu dira: igoera [54-62], murrizketa [63] eta aldaketarik eza [64-68].

$\alpha$-sinukleina oligomerikoaren determinazioak ere ez du emaitza homogeneorik erakusten. Horrela, bi ikerlanen arabera, proteoforma horren maila handiagoa da Parkinsona duten pazienteen plasman kontrol osasuntsuen plasman baino $[69,70]$. Emelyanov-ek eta haren kolaboratzaileek, ordea, Parkinson gaixotasunean maila txikiagoan aurkitzen dute [65], eta beste ikerlan batek ez du aldaketarik deskribatzen [63]. Azkenik, badirudi $\alpha$-sinukleina fosforilatuaren maila handituta dagoela Parkinsona duten pazienteen plasman.

\subsection{Alfa-sinukleinaren mailak beste gorputzeko fluido batzuetan}

Parkinson gaixotasunean listu-guruinak kaltetuta daude, eta Lewyren gorputzen patologia erakusten dute fase goiztiarretan. Listu-guruin horiek sortzen duten listua biofluido erakargarria izan daiteke, bere irisgarritasun eta homogeneotasunagatik, odol-kutsadurarik ez duelako eta hura lortzeko teknikak ez-inbaditzaileak direlako. Hala ere, gaur egun existitzen den ebidentzia eskasa eta kontraesankorra da. Datuek Parkinsona duten pazienteen listuaren $\alpha$-sinukleina totalaren mailak, kontrol osasuntsuekin alderatuta, murriztuta daudela edo bere horretan mantentzen direla erakusten dute [71-73]. Aitzitik, $\alpha$-sinukleina oligomerikoaren mailak eta $\alpha$-sinukleina oligomerikoa/totala ratioa neurtzean, balio horiek Parkinson pazienteen artean handiagoak direla ikusi da [74-77]. Gaur egun, datuen koherentzia faltaren eraginez, Parkinson gaixotasunaren diagnostikorako listuko $\alpha$-sinukleina zehazteak ez du lortu praktika klinikoan sartzeko behar besteko ebidentzia.

Listuaz gain, malkoak biomarkatzaile-iturri ezagunak dira begiko gaixotasun zein gaixotasun sistemikoetarako, abantaila bereziak eskaintzen 
baitituzte: lagin-bilketa ez da teknika inbaditzailea, eta proteina-konposizioa gero eta hobeto definitua dago. Parkinson gaixotasunean malkoetan $\alpha$-sinukleina oligomerikoa nabarmen handitzen dela frogatu da, kontrol osasuntsuekin alderatuta [78, 79]. Azken ikerketek, ultrasentikorra den entsegu bat erabiliz, frogatu dute $\alpha$-sinukleina totalaren maila ere areagotuta dagoela Parkinson pazienteen malkoetan [80].

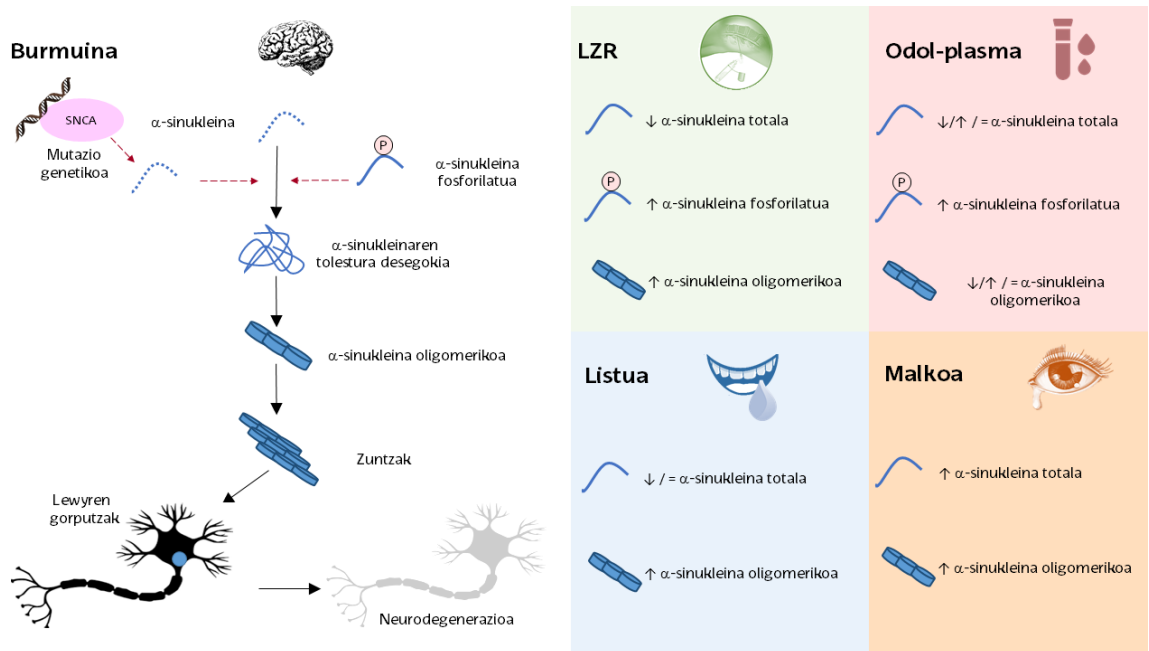

2. irudia. Hainbat faktorek a-sinukleina tolestura desegokia eragin dezakete; hala nola, mutazio genetikoek edo itzulpen osteko proteinaren aldaketek (fosforilazioa). Behin osatuta, desegoki tolestutako a-sinukleinak oligomero disolbagarrietan antolatzeko joera du, eta, azkenik, zuntz disolbaezinetan, zeinak Lewyren gorputzen osagai nagusia diren. Parkinsona duten pazienteetan, fluido biologiko batzuek profil biokimiko berezia erakusten dute, eta irudi honetan, fluido biologiko horietan a-sinukleinaren proteoformen mailak nola aldatzen diren laburbiltzen da. Alterazio horiek baliagarriak izan daitezke Parkinson gaixotasunaren diagnostiko goiztiarrerako.

\section{ONDORIOAK}

Gaur egun Parkinson gaixotasunaren diagnostiko goiztiarra egiteko dauden zailtasunak direla eta, ezinbestekoa da eraginkorrak diren eta modu errazean lor daitezkeen biomarkatzaileak aurkitzea, Parkinsonaren diagnostikoa modu fidagarrian burutzeko, eta gaixotasunaren larritasuna modu objektiboan neurtzeko. Diagnostiko-biomarkatzaileen arloan, etorkizun handiko emaitzak lortu dira gaixotasunaren mekanismo fisiopatologikoekin lotutako molekulak aztertuz, eta, Parkinson gaixotasunaren kasuan, a-sinukleinaren proteoformak lirateke hautagai nagusiak. 
Gorputzeko biofluido desberdinetako laginetan egindako ikerketen arabera, $\alpha$-sinukleinaren kontzentrazioa Parkinson gaixotasunaren diagnostiko goiztiar eta larritasunerako biomarkatzaile gisa erabiltzeko aukerak daude. Hala ere, oraindik muga teknikoak gainditzeke daude; hala nola, hemoglobinaren kutsadura, teknika desberdinen arteko aldakortasuna edo teknika berdinen arteko errepikakortasuna. Ikerketa gehienek LZRan a-sinukleina totalaren mailak ebaluatu dituzte, eta Parkinson pazienteen proteina-maila totalen murrizketa erakusten dute, kontrol osasuntsuekin alderatuta. Hala ere, zehaztasun diagnostikoa txikia denez, biomarkatzaile hori, berez, ezin izango litzateke erabilgarritzat jo Parkinson gaixotasunaren diagnostikoan. LZRan ere a-sinukleina fosforilatua eta oligomerikoa handituta daudela frogatu da, baina datu gehiago beharrezkoak dira haien balio diagnostiko potentziala baieztatzeko. LZR lortzeko zailtasun teknikoa kontuan hartuta, a-sinukleina espezieen mailak ikertu dira eskuragarriagoak diren beste biofluido batzuetan; besteak beste, odol-plasman, listuan edo malkoetan. Hala ere, lortutako emaitzak ez dira eztabaidaezinak, segur aski, hainbat nahastefaktorek eta prozedura analitikok eraginda.

Gainera, kontuan izan behar da, ikerlan gutxi egin direla Parkinson gaixotasunaren fase goiztiarretan (hau da, Parkinsonaren fase aurre-motorrean). Fase horretan, biomarkatzaileak beharko lirateke diagnostiko zehatza egiteko. Bestalde, luzetarako ikerketa gutxi burutu dira $\alpha$-sinukleinaren eta haren proteoformen mailak nola aldatzen diren deskribatzen dutenak, eta hori ezinbestekoa da $\alpha$-sinukleinaren balio potentziala aztertzeko Parkinson gaixotasunaren monitorizaziorako biomarkatzaile gisa.

Azken bi urteetan teknologiak izan dituen aurrerapenak ikusita, eta jakinda jadanik eskuragai daudela erabat sentsibleak eta errepikakorrak diren teknika aurreratuak $\alpha$-sinukleinaren detekziorako, hurrengo urteetan orain arte izandako eragozpen guztiei irtenbidea emango zaie. Beraz, laster zehaztuko da Parkinsonaren egungo biomarkatzaile hautagai nagusiek gaixotasunaren diagnostiko egokia egin dezaketen, Parkinson gaixotasunaren larritasunarekin erlazionatuta dauden edota gaixotasunaren ibilbide klinikoa aurreikus dezaketen.

\section{BIBLIOGRAFIA}

[1] Gómez-Benito, M., Granado, N., García-Sanz, P., Michel, A., Dumoulin, M., Moratalla, R. 2020. «Modeling Parkinson's Disease With the Alpha-Synuclein Protein». Frontiers in Pharmacology, 11, 1-15.

[2] R., García-Ramos, E., López, Valdés, L., Ballesteros, S., Jesús, P., Mi. 2016. «Informe de la Fundación del Cerebro sobre el impacto social de la enfermedad de Parkinson en España». Neurología, 31, 401-413. 
[3] Dorsey, E. R., Sherer, T., Okun, M. S., Bloemd, B. R. 2018. «The emerging evidence of the Parkinson pandemic». Journal of Parkinson's Disease, 8, S3-S8.

[4] GBD 2016 Disease and InJury Incidence and Prevalence CollaboraTORS. 2017. «Global, regional, and national incidence, prevalence, and years lived with disability for 328 diseases and injuries for 195 countries, 19902016: A systematic analysis for the Global Burden of Disease Study 2016». The Lancet, 390, 1211-1259.

[5] Ruipérez, V., Darios, F., Davletov, B. 2010. «Alpha-synuclein, lipids and Parkinson's disease». Progress in Lipid Research, 49, 420-428.

[6] Trigo-Damas, I., Del Rey, N. L. G., Blesa, J. 2018. «Novel models for parkinson's disease and their impact on future drug discovery». Expert Opinion on Drug Discovery, 13, 229-239.

[7] Bellucci, A., Mercuri, N. B., Venneri, A., Faustini, G., Longhena, F., PiZZI, M., Missale, C., Spano, P. 2016. «Parkinson's disease: From synaptic loss to connectome dysfunction». Neuropathology and Applied Neurobiology, 42, 77-94.

[8] Emamzadeh, F. N., Surguchov, A. 2018. «Parkinson's disease: Biomarkers, treatment, and risk factors». Frontiers in Neuroscience, 12, 1-14.

[9] De Deurwaerdère, P., Di Giovanni, G., Millan, M. J. 2017. «Expanding the repertoire of L-DOPA's actions: A comprehensive review of its functional neurochemistry». Progress in Neurobiology, 151, 57-100.

[10] Pereira Da Silva-Júnior, F., Braga-Neto, P., Sueli Monte, F., Meireles SAles De BRuin, V. 2005. «Amantadine reduces the duration of levodopainduced dyskinesia: A randomized, double-blind, placebo-controlled study». Parkinsonism and Related Disorders, 11, 449-452.

[11] TARAKad, A., Jankovic, J. 2017. «Diagnosis and Management of Parkinson's Disease». Seminars in Neurology, 37, 118-126.

[12] Connolly, B. S., LANG, A. E. 2014. «Pharmacological treatment of Parkinson disease: A review». JAMA-Journal of the American Medical Association, 311, 1670-1683.

[13] Lotankar, S., Prabhavalkar, K. S., Bhatt, L. K. 2017. «Biomarkers for Parkinson's Disease : Recent Advancement». Neuroscience Bulletin, 33, 585-597.

[14] Miller, D. B., Callaghan, J. P. O. 2016. «Biomarkers of Parkinson's disease : Present and future», 64, 1-13.

[15] Postuma, R. B., Berg, D., Stern, M., Poewe, W., Olanow, C. W., Oertel, W., Obeso, J., MareK, K., Litvan, I., Lang, A. E., Halliday, G., Goetz, C. G., Gasser, T., Dubois, B., Chan, P., Bloem, B. R., Adler, C. H., DeusCHL, G. 2015. «MDS clinical diagnostic criteria for Parkinson's disease». Movement Disorders, 30, 1591-1601.

[16] Beyer, K., Domingo-SÀBat, M., Ariza, A. 2009. «Molecular pathology of lewy body diseases». International Journal of Molecular Sciences, 10, 724745 . 
[17] Dickson, D. W. 2018. «Neuropathology of Parkinson disease». Parkinsonism and Related Disorders, 46, S30-S33.

[18] Jellinger, K. A. 2010. «Basic mechanisms of neurodegeneration: A critical update». Journal of Cellular and Molecular Medicine, 14, 457-487.

[19] Carrell, R. W., Lomas, D. A. 1997. «Conformational disease». Lancet, 350, 134-138.

[20] KIm GH, Kim JE, RhIE SJ, Y. S. 2015. «The Role of Oxidative Stress in Neurodegenerative Diseases». Experimental Neurobiology, 24, 325-340.

[21] Du G, LEwIS MM, SicA C, et al. 2018. «Distinct progression pattern of susceptibility MRI in the substantia nigra of Parkinson's patients.». Movement Disorders, 33, 1423-1431.

[22] Garcia-Esparcia, P., Hernández-Ortega, K., Koneti, A., Gil, L., DelGado-Morales, R., Castaño, E., Carmona, M., Ferrer, I. 2015. «Altered machinery of protein synthesis is region- and stage-dependent and is associated with $\alpha$-synuclein oligomers in Parkinson's disease». Acta Neuropathologica Communications, 3, 1-25.

[23] Johnson, R., AND Strehler, B. L. 1972. «Loss of genes coding for ribosomal RNA in ageing brain cells.». Nature, 240, 412-414.

[24] Parlato, R., Kreiner, G. 2013. «Nucleolar activity in neurodegenerative diseases: A missing piece of the puzzle?». Journal of Molecular Medicine, 91, 541-547.

[25] Scheper, W., Hoozemans, J. J. M. 2015. «The unfolded protein response in neurodegenerative diseases: a neuropathological perspective». Acta Neuropathologica, 130, 315-331.

[26] Dantuma, N. P., BotT, L. C. 2014. «The ubiquitin-proteasome system in neurodegenerative diseases: Precipitating factor, yet part of the solution». Frontiers in Molecular Neuroscience, 7, 1-18.

[27] Dickson, D. W. 2012. «Parkinson's disease and parkinsonism in». Cold Spring,Med, Harb Perspect, 2, 1-15.

[28] Wakabayashi, K., Tanji, K., Mori, F., Takahashi, H. 2007. «The Lewy body in Parkinson's disease: Molecules implicated in the formation and degradation of $\alpha$-synuclein aggregates». Neuropathology, 27, 494-506.

[29] Mahul-Mellier, A. L., Burtscher, J., Maharjan, N., Weerens, L., CroiSier, M., Kuttler, F., Leleu, M., Knott, G. W., Lashuel, H. A. 2020. «The process of Lewy body formation, rather than simply $\alpha$-synuclein fibrillization, is one of the major drivers of neurodegeneration». Proceedings of the National Academy of Sciences of the United States of America, 117, 4971-4982.

[30] Spillantini MG, Schmidt ML, Lee VM, Trojanowski JQ, Jakes R, G. M. 1997. «a -Synuclein in Lewy bodies». Nature, 388, 839-840.

[31] Braak, H., Del Tredici, K., Rüb, U., De Vos, R. A. I., Jansen Steur, E. N. H., BRAAK, E. 2003. «Staging of brain pathology related to sporadic Parkinson's disease». Neurobiology of Aging, 24, 197-211.

[32] Dickson, D. W., Fujishiro, H., DelleDonne, A., Menke, J., Ahmed, Z., Klos, K. J., Josephs, K. A., Frigerio, R., Burnett, M., Parisi, J. R., Ahls- 
KOG, J. E. 2008. «Evidence that incidental Lewy body disease is pre-symptomatic Parkinson's disease». Acta Neuropathologica, 115, 437-444.

[33] Martín, X. E., , Fernando Gómez Bustob, M. C. G. F. y M. M. De P. 2011. «Papel de la genética en la etiología de las sinucleinopatías Xabier». Revista Española de Geriatría y Gerontología, 46, 3-11.

[34] FERnÁndEZ-EsPejo, E. 2013. «Agregación De Alfa-Sinucleína Y Degeneración Parkinsoniana». Fisiología 17-19.

[35] Lee, V. M. Y., Trojanowski, J. Q. 2006. «Mechanisms of Parkinson's Disease Linked to Pathological $\alpha$-Synuclein: New Targets for Drug Discovery». Neuron, 52, 33-38.

[36] XU, L., Pu, J. 2016. «Alpha-Synuclein in Parkinson's Disease: From Pathogenetic Dysfunction to Potential Clinical Application». Parkinson's Disease, 2016, DOI: $10.1155 / 2016 / 1720621$.

[37] Parnetti, L., Gaetani, L., Eusebi, P., Paciotti, S., Hansson, O., El-Agnaf, O., Mollenhauer, B., Blennow, K., Calabresi, P. 2019. «CSF and blood biomarkers for Parkinson's disease». The Lancet Neurology, 18, 573586.

[38] Masuda, M., Suzuki, N., Taniguchi, S., Oikawa, T., Nonaka, T., Iwatsubo, T., Hisanaga, S. I., Goedert, M., Hasegawa, M. 2006. «Small molecule inhibitors of $\alpha$-synuclein filament assembly». Biochemistry, 45, 60856094.

[39] Sako, W., Murakami, N., Izumi, Y., KaJi, R. 2014. «Reduced alpha-synuclein in cerebrospinal fluid in synucleinopathies: Evidence from a metaanalysis». Movement Disorders, 29, 1599-1605.

[40] Liang Gao, Hongmei Tang, Kun Nie, Limin Wang, Jiehao Zhao, Rong Gan, Jing Huang, Ruiming Zhu, Shujun Feng, Zhenpeng Duan, Y. Z. \& L. W. 2015. «Cerebrospinal fluid alpha-synuclein as a biomarker for Parkinson's disease diagnosis: A systematic review and meta-analysis». International Journal of Neuroscience, 125, 645-654.

[41] Zhou, B., Wen, M., Yu, W. F., Zhang, C. L., JiaO, L. 2015. «The diagnostic and differential diagnosis utility of cerebrospinal fluid $\alpha$-synuclein levels in Parkinson's disease: A meta-analysis». Parkinson's Disease, 2015, DOI: $10.1155 / 2015 / 567386$.

[42] Eusebi, P., Giannandrea, D., Biscetti, L., Abraha, I., Chiasserini, D., Orso, M., Calabresi, P., Parnetti, L. 2017. «Diagnostic utility of cerebrospinal fluid $\alpha$-synuclein in Parkinson's disease: A systematic review and meta-analysis». Movement Disorders, 32, 1389-1400.

[43] Mollenhauer, B., Parnetti, L., Rektorova, I., Kramberger, M. G., Pikkarainen, M., Schulz-Schaeffer, W. J., Aarsland, D., Svenningsson, P., Farotti, L., Verbeek, M. M., Schlossmacher, M. G. 2016. «Biological confounders for the values of cerebrospinal fluid proteins in Parkinson's disease and related disorders». Journal of Neurochemistry, 139, 290-317.

[44] Wennström, M., Surova, Y., Hall, S., Nilsson, C., Minthon, L., BosTRÖM, F., Hansson, O., NiElSEN, H. M. 2013. «Low CSF Levels of Both 
$\alpha$-Synuclein and the $\alpha$-Synuclein Cleaving Enzyme Neurosin in Patients with Synucleinopathy». PLOS ONE, 8, DOI: 10.1371/journal.pone.0053250.

[45] Magdalinou, N. K., Paterson, R. W., Schott, J. M., Fox, N. C., Mummery, C., Blennow, K., Bhatia, K., Morris, H. R., Giunti, P., Warner, T. T., De Silva, R., Lees, A. J., \& Zetterberg, H. 2015. «A panel of nine cerebrospinal fluid biomarkers may identify patients with atypical parkinsonian syndromes». Journal of Neurology, Neurosurgery and Psychiatry, 86, 1240-1247.

[46] Majbour, N. K., Vaikath, N. N., Van Dijk, K. D., Ardah, M. T., Varghese, S., Vesterager, L. B., Montezinho, L. P., Poole, S., Safieh-Garabedian, B., Tokuda, T., Teunissen, C. E., Berendse, H. W., Van De Berg, W. D. J., El-AGNAF, O. M. A. 2016. «Oligomeric and phosphorylated alphasynuclein as potential CSF biomarkers for Parkinson's disease». Molecular Neurodegeneration, 11, 1-15.

[47] Hansson, O., Hall, S., Öhrfelt, A., Zetterberg, H., Blennow, K., Minthon, L., NäGGa, K., Londos, E., Varghese, S., Majbour, N. K., Al-HaYANI, A., EL-AGNAF, O. M. 2014. «Levels of cerebrospinal fluid $\alpha$-synuclein oligomers are increased in Parkinson's disease with dementia and dementia with Lewy bodies compared to Alzheimer's disease». Alzheimer's Research and Therapy, 6, 4-9.

[48] Zuo, L. J., Yu, S. Y., Wang, F., Hu, Y., PiaO, Y. S., Du, Y., Lian, T. H., Wang, R. D., Yu, Q. J., Wang, Y. J., Wang, X. M., Chan, P., Chen, S. DI, WANG, Y., ZHANG, W. 2016. «Parkinson's disease with fatigue: Clinical characteristics and potential mechanisms relevant to $\alpha$-synuclein oligomer». Journal of Clinical Neurology (Korea), 12, 172-180.

[49] van Steenoven, I., Majbour, N. K., Vaikath, N. N., Berendse, H. W., VAN DER Flier, W. M., van de Berg, W. D. J., Teunissen, C. E., Lemstra, A. W., El-Agnaf, O. M. A. 2018. « $\alpha$-Synuclein species as potential cerebrospinal fluid biomarkers for dementia with lewy bodies». Movement $D i$ sorders, 33, 1724-1733.

[50] Majbour, N. K., Aasly, J. O., Hustad, E., Thomas, M. A., Vaikath, N. N., Elkum, N., Van De Berg, W. D. J., Tokuda, T., Mollenhauer, B., BerendSe, H. W., El-Agnaf, O. M. A. 2020. «CSF total and oligomeric $\alpha$-Synuclein along with TNF- $\alpha$ as risk biomarkers for Parkinson's disease: A study in LRRK2 mutation carriers». Translational Neurodegeneration, 9, $1-10$.

[51] Oosterveld, L. P., Verberk, I. M. W., Majbour, N. K., El-Agnaf, O. M., Weinstein, H. C., Berendse, H. W., Teunissen, C. E., van de Berg, W. D. J. 2020. «CSF or serum neurofilament light added to $\alpha$-Synuclein panel discriminates Parkinson's from controls». Movement Disorders, 35, 288295.

[52] El-Agnaf, O. M. A., Salem, S. A., Paleologou, K. E., Cooper, L. J., Fullwood, N. J., Gibson, M. J., Curran, M. D., Court, J. A., Mann, D. M. A., IKEDA, S.-I., COOKSON, M. R., HARDY, J., Allsop, D. 2003. « $\alpha$-Synuclein 
implicated in Parkinson's disease is present in extracellular biological fluids, including human plasma». The FASEB Journal, 17, 1-16.

[53] Barbour, R., Kling, K., Anderson, J. P., Banducci, K., Cole, T., Diep, L., Fox, M., Goldstein, J. M., Soriano, F., Seubert, P., Chilcote, T. J. 2008. «Red blood cells are the major source of alpha-synuclein in blood». Neurodegenerative Diseases, 5, 55-59.

[54] Lee, P. H., Lee, G., PArk, H. J., Bang, O. Y., Joo, I. S., Huh, K. 2006. «The plasma alpha-synuclein levels in patients with Parkinson's disease and multiple system atrophy». Journal of Neural Transmission, 113, 1435-1439.

[55] Duran, R., Barrero, F. J., Morales, B., Luna, J. D., Ramirez, M., \& VIVES, F. 2010. «Plasma $\alpha$-synuclein in patients with Parkinson's disease with and without treatment.». Movement Disorders, 25, 489-493.

[56] Ding, J., Zhang, J., Wang, X., Zhang, L., Jiang, S., Yuan, Y., Li, J., Zhu, L., ZHANG, K. 2017. «Relationship between the plasma levels of neurodegenerative proteins and motor subtypes of Parkinson's disease». Journal of Neural Transmission, 124, 353-360.

[57] Lin, C. H., Yang, S. Y., Horng, H. E., Yang, C. C., Chieh, J. J., Chen, H. H., LIU, B. H., CHIU, M. J. 2017. «Plasma $\alpha$-synuclein predicts cognitive decline in Parkinson's disease». Journal of Neurology, Neurosurgery and Psychiatry, 88, 818-824.

[58] Lin, C. H., Yang, S. Y., Horng, H. E., Yang, C. C., Chieh, J. J., Chen, H. H., LiU, B. H., ChIU, M. J. 2018. «Plasma biomarkers differentiate Parkinson's disease from atypical parkinsonism syndromes». Frontiers in Aging Neuroscience, 10, 1-9.

[59] Lin, Liu, YANG, YANG, Wu, Chiu. 2019. «Plasma pS129- $\alpha$-Synuclein Is a Surrogate Biofluid Marker of Motor Severity and Progression in Parkinson's Disease». Journal of Clinical Medicine, 8, 1601.

[60] NG, A. S. L., Tan, Y. J., Lu, Z., NG, E. Y. L., NG, S. Y. E., ChiA, N. S. Y., Setiawan, F., Xu, Z., Tay, K. Y., Prakash, K. M., Au, W. L., Tan, E. K., TAN, L. C. S. 2019. «Plasma alpha-synuclein detected by single molecule array is increased in PD». Annals of Clinical and Translational Neurology, 6, 615-619.

[61] Chang, C. W., Yang, S. Y., Yang, C. C., Chang, C. W., Wu, Y. R. 2020. «Plasma and Serum Alpha-Synuclein as a Biomarker of Diagnosis in Patients With Parkinson's Disease». Frontiers in Neurology, 10, 1-7.

[62] Chen, N. C., Chen, H. L., Li, S. H., Chang, Y. H., Chen, M. H., Tsai, N. W., Yu, C. C., YANG, S. Y., Lu, C. H., Lin, W. C. 2020. «Plasma Levels of $\alpha$-Synuclein, $A \beta-40$ and T-tau as Biomarkers to Predict Cognitive Impairment in Parkinson's Disease». Frontiers in Aging Neuroscience, 12, $1-8$.

[63] Gorostidi, A., Bergareche, A., Ruiz-Martínez, J., Martí-Massó, J. F., Cruz, M., Varghese, S., Qureshi, M. M., Alzahmi, F., Al-Hayani, A., De Munáin, A. L., El-Agnaf, O. M. A. 2012. « $\alpha$-Synuclein Levels in Blood Plasma from LRRK2 Mutation Carriers». PLoS ONE, 7, 1-6. 
[64] Foulds, P. G., Diggle, P., Mitchell, J. D., Parker, A., Hasegawa, M., Masuda-Suzukake, M., Mann, D. M. A., Allsop, D. 2013. «A longitudinal study on a-synuclein in blood plasma as a biomarker for Parkinson's disease». Scientific Reports, 3, 1-6.

[65] Emelyanov, A., Andoskin, P., Pchelina, S. 2017. «Dataset of total, oligomeric alpha-synuclein and hemoglobin levels in plasma in Parkinson's disease». Data in Brief, 10, 182-185.

[66] Cerri, S., Ghezzi, C., Sampieri, M., Siani, F., Avenali, M., Dornini, G., Zangaglia, R., Minafra, B., Blandini, F. 2018. «The exosomal/total $\alpha$-synuclein ratio in plasma is associated with glucocerebrosidase activity and correlates with measures of disease severity in PD patients». Frontiers in Cellular Neuroscience, 12, 1-10.

[67] Malec-Litwinowicz, M., Plewka, A., Plewka, D., Bogunia, E., MoReK, M., SZCZudliK, A., SZubiga, M., RudZińSKa-BAR, M. 2018. «The relation between plasma $\alpha$-synuclein level and clinical symptoms or signs of Parkinson's disease». Neurologia i Neurochirurgia Polska, 52, 243-251.

[68] Chahine, L. M., Beach, T. G., Brumm, M. C., Adler, C. H., Coffey, C. S., Mosovsky, S., Caspell-Garcia, C., Serrano, G. E., Munoz, D. G., White, C. L., Crary, J. F., Jennings, D., TAYlor, P., Foroud, T., Arnedo, V., KoPil, C. M., Riley, L., Dave, K. D., Mollenhauer, B. 2020. «In vivo distribution of $\alpha$-synuclein in multiple tissues and biofluids in Parkinson disease». Neurology, 95, e1267-e1284.

[69] Chen, X. Q., Niu, J. P., Peng, R. Q., Song, Y. H., Xu, N., Zhang, Y. W. 2019. «The early diagnosis of Parkinson's disease through combined biomarkers». Acta Neurologica Scandinavica, 140, 268-273.

[70] Wang, X., Chi, J., Huang, D., Ding, L., ZhaO, X., Jiang, L., Yu, Y., GaO, F. 2019. « $\alpha$-synuclein promotes progression of Parkinson's disease by upregulating autophagy signaling pathway to activate NLRP3 inflammasome». Experimental and Therapeutic Medicine 931-938.

[71] Devic, I., Hwang, H., Edgar, J. S., Izutsu, K., Presland, R., Pan, C., Goodlett, D. R., Wang, Y., Armaly, J., Tumas, V., Zabetian, C. P., LeveReNZ, J. B., ShI, M., ZhAng, J. 2011. «Salivary $\alpha$-synuclein and DJ-1: Potential biomarkers for Parkinson's disease». Brain, 134, DOI: 10.1093/brain/ awr015.

[72] Al-Nimer, M. S. M., Mshatat, S. F., Abdulla, H. I. 2014. «Saliva $\alpha$-synuclein and a high extinction coeffi cient protein: A novel approach in assessment biomarkers of parkinson's disease». North American Journal of Medical Sciences, 6, 633-637.

[73] Stewart, T., Sui, Y. T., Gonzalez-Cuyar, L. F., Wong, D. T., Akin, D. M., Tumas, V., Aasly, J., Ashmore, E., Aro, P., Ginghina, C., KorfF, A., Zabetian, C. P., Leverenz, J. B., Shi, M., \& Zhang, J. 2014. «Cheek cell-derived $\alpha$-synuclein and DJ-1 do not differentiateParkinson's disease from control». Neurobiology of Aging, 35, 418-420. 
[74] Kang, W., Chen, W., Yang, Q., Zhang, L., Zhang, L., Wang, X., Dong, F., Zhao, Y., Chen, S., Quinn, T. J., Zhang, J., Chen, S., LiU, J. 2016. «Salivary total $\alpha$-synuclein, oligomeric $\alpha$-synuclein and SNCA variants in Parkinson's disease patients». Scientific Reports, 6, 1-8.

[75] Vivacqua, G., Latorre, A., Suppa, A., Nardi, M., Pietracupa, S., ManCinelli, R., Fabbrini, G., Colosimo, C., Gaudio, E., Berardelli, A. 2016. «Abnormal salivary total and oligomeric alpha-synuclein in Parkinson's disease». PLoS ONE, 11, 1-12.

[76] CaO, Z., Wu, Y., Liu, G., Jiang, Y., Wang, X., Wang, Z., Zhang, J., Feng, T. 2019. « $\alpha$-Synuclein in salivary extracellular vesicles as a potential biomarker of Parkinson's disease». Neuroscience Letters, 696, 114-120.

[77] Vivacqua, G., Suppa, A., Mancinelli, R., Belvisi, D., Fabbrini, A., Costanzo, M., Formica, A., Onori, P., Fabbrini, G., Berardelli, A. 2019. «Salivary alpha-synuclein in the diagnosis of Parkinson's disease and Progressive Supranuclear Palsy». Parkinsonism and Related Disorders, 63, 143148.

[78] Hamm-Alvarez, S. F., Okamoto, C. T., Janga, S. R., Feigenbaum, D., Edman, M. C., Freire, D., Shah, M., Ghanshani, R., Mack, W. J., LeW, M. F. 2018. «Oligomeric $\alpha$-synuclein is increased in basal tears of Parkinson's patients». Biomarkers in Medicine, 13, 941-952.

[79] Hamm-Alvarez, S. F., Janga, S. R., Edman, M. C., Feigenbaum, D., Freire, D., Mack, W. J., Окамото, C. T., Lew, M. F. 2019. «Levels of oligomeric $\alpha$-Synuclein in reflex tears distinguish Parkinson's disease patients from healthy controls». Biomarkers in Medicine, 13, 1447-1457.

[80] Maass, F., Rikker, S., Dambeck, V., Warth, C., Tatenhorst, L., Csoti, I., Schmitz, M., Zerr, I., LeHA, A., BäHr, M., LingOR, P. 2020. «Increased alpha-synuclein tear fluid levels in patients with Parkinson's disease». Scientific Reports, 10, 1-5. 
